\title{
La deificación del dinero en contravía de la integridad de la profesión contable*
}

\author{
Nataly Gualtero Guarnizo
}

Gualtero G., N. (2011). La deificación del dinero en contravía de la integridad de la profesión contable. Revista Activos, 16 y 17, 35-50.

JEL: J30

Recibido: 24 de febrero de 2011 Aprobado: 27 de marzo de 2011

\section{Resumen}

Ante la desdicha que ocasionan los escándalos en los que la contaduría pública termina inmiscuida, este documento plantea una serie de críticas sobre la preponderancia que el dinero ha tenido en las acciones contables, lo cual va en detrimento de la integridad del contador público. Es una invitación para el cambio y para reencontrar la pasión por la profesión contable, a partir de un clamor poético.

\section{Palabras clave}

Contador público, corrupción, dinero, ética, pasión.

* $\quad$ Este artículo es resultado de la labor desarrollada en el grupo de trabajo académico del programa de Contaduría Pública de la Universidad Cooperativa de Colombia, Seccional Bogotá. La autora agradece el diálogo continuo que en el grupo se desarrolla junto con el profesor Juan Camilo León Saavedra; diálogo en el que aprendizaje mutuo marca la pauta para las reflexiones sobre nuestra profesión. 
Gualtero G., N. (2011). Money Worship Against Accountancy Integrity. Activos Review, 16 and 17, 35-50.

\begin{abstract}
Because of the sorrow that causes the financial scandals that involve Public Accountants, this paper presents a number of criticism about the preponderance of money in the accountant's actions, which go in prejudice of the Public Accountant integrity. This paper is an invitation to change and to find again the passion about accountant's labor based on a poetic call.
\end{abstract}

\title{
Keywords
}

Public accountant, corruption, money, ethics, passion.

Gualtero G., N. (2011). La déification de l'argent contraire à l'intégrité de la profession comptable. Revue Activos, 16 et 17, 35-50.

\section{Résumé}

Devant le malheur occasionné par les scandales auxquels la Comptabilité Publique est mêlée, ce document propose une série de réflexions critiques sur la prépondérance que l'argent a eue dans les actions comptables au détriment de l'intégrité du comptable, qui se veulent une invitation au changement et à une nouvelle rencontre avec la passion pour la profession comptable à partir d'une clameur poétique.

\section{Mots-clés}

Comptable public, corruption, argent, éthique, passion.

\section{Introducción}

En la actualidad, el ser humano está rodeado de situaciones que tienen un factor común: la corrupción. La indiferencia presente en la sociedad ha traído como consecuencia la pérdida de credibilidad en las personas e instituciones; en general, 
las cualidades humanas desaparecen y las relaciones sociales se definen en función del dinero y el poder.

El fraude hace parte del día a día, se evidencia desde pequeñas situaciones como tomar "prestados" $\$ 1000$ de la caja menor, hasta la realización de grandes desfalcos financieros. Es una realidad que golpea a un sinnúmero de profesiones y, más aún, a aquellas que cuenta con un papel relevante en las decisiones organizacionales, como es el caso de la profesión contable.

La contaduría pública tiene características únicas deseadas por otras profesiones, pero es aún más asediada por personas que buscan utilizarla como una herramienta para el desarrollo de diversos fraudes, los cuales tienen como base el aprovechamiento de la confianza entregada. Ante esta situación, en la profesión contable la fe pública debe coexistir con la ética, siendo ésta el escudo con que cuenta el contador público para protegerse no sólo de las diversas situaciones en las que se ve envuelto, sino de propuestas inescrupulosas que llegan a golpear su puerta. Allí la independencia mental puede verse limitada por la dependencia económica.

En esta época es evidente cómo en cada semestre se matriculan un gran número de estudiantes en los programas de contaduría pública, pero, a su vez, un amplio porcentaje de estos alumnos fundamentan la elección de esta bella profesión en motivos diferentes al verdadero gusto por ésta. Es desde ese momento en que inicia la formación de estudiantes que quizá nunca se enamorarán de la profesión contable, siendo así más sencillo traicionarla y perder los escrúpulos.

Este documento busca cautivar a estudiantes, docentes y profesionales de la contaduría pública, quienes tienen la responsabilidad de proteger sus principios, no darle un valor monetario a su conciencia, luchar por el respeto que merece la fe pública, despertar la sed de conocimiento y dimensionar el efecto de su actuar en su entorno y en su propio ser. Lo anterior se encuentra fundamentado en reflexiones críticas acerca del dinero, la ética en debate, la permisividad de la sociedad frente a la corrupción, el conformismo cognitivo y la sensibilización poética.

Así, primero se trabajará sobre el fraude fundamentado en el interés por el dinero, lo que deriva en un detrimento de la humanidad; luego se abordará la "miopía" 
respecto a la ética, a causa del olvido de las buenas costumbres en la profesión; posteriormente se reflexionará sobre cómo esta problemática está quebrando el actuar del contador; finalmente se hará el reencuentro con la ética y la poesía, para despertar la pasión por la profesión contable.

\section{Fraude: camos o esclavos del dinero?}

Nos encontramos en una sociedad en la que la contaminación del ser es cada vez más grande; el smog llamado dinero se ha encargado de desplazar la pureza de la humanidad del hombre, para llevarlo a un estado de "salvajismo" en el que los efectos a los semejantes no son impedimento para alcanzar los objetivos individuales. "Cualquier colombiano lo sabe: aquí nada sirve a un propósito público. Aquí sólo existen intereses particulares” (Ospina, 1997: 14).

El dinero, aquel papel sin equilibrio, se ha convertido en un fin que al ser alcanzado sigue dejando vacíos y se convierte, por consiguiente, en una obsesión. Si bien el dinero en sí mismo no es malo, hay que cuestionar lo que se puede llegar a hacer para conseguirlo.

Se ha perdido la sensibilidad para ver el sufrimiento de los demás; el ser humano se ha convertido en una simple marioneta del poder y el dinero ha dejado de ser el medio de satisfacer necesidades, para convertirse en un fin que brinda una supuesta felicidad. ¿Qué sentido tiene tener dinero cuando se es portada en la prensa tildado como corrupto? ¿De qué sirve el dinero cuando no se tiene la tranquilidad para usarlo?

Son diversos los escándalos por fraudes que se encuentran a través del tiempo, y en la actualidad la situación no cambia. "Fraude es un acto o muchos actos diseñados intencionalmente para engañar a otra persona y causarle una pérdida financiera" (Sánchez, 2009: 10). Claros ejemplos se evidencian en entidades privadas, como es el caso de DMG y el de los hermanos Nule, pero las entidades estatales tampoco escapan a esta realidad; prueba de ello son las irregularidades encontradas en la Alcaldía de Bogotá y en las obras nacionales del anterior gobierno. Sin embargo, es pertinente preguntarse: ¿ ¿cuál es la razón para que la corrupción sobreviva, aun 
conociendo los efectos que tiene en la sociedad? La contaduría no es ajena a esta problemática. Según Ruiz, el fraude en el reporte financiero "consiste en omisiones o presentaciones erradas e intencionales de valores o revelaciones en los estados financieros, efectuadas para engañar a sus usuarios, las cuales son definidas como fraudulentas, mediante un proceso administrativo, civil o criminal" (2008: 257).

No obstante, aun siendo conocedores de esto, parece no importarnos que la corrupción forme parte integral de nuestras vidas: se perdieron los escrúpulos, es como si a la sociedad le agradara vivir engañada.

El oxígeno con que respira la corrupción es la permisibilidad, donde vender la conciencia por unas cuantas monedas es más común de lo que se cree, y frases como el CVY (cómo voy yo) dejan de ser un chiste, para convertirse en una realidad. Se constituye así la doble moral de la que muchas personas hacen uso, a partir de la cual lo malo deja de ser tal hasta que la persona lo hace; entonces ¿ dónde queda la dignidad? "Dignidad", palabra indescifrable que, sin embargo, pretende decirlo todo (Cruz, 2005: 5). ¿Dónde están los apuntes de ética de la universidad?

\section{Miopía frente a la ética}

La frialdad que envuelve el proceder del ser humano ha sido parte integral de la historia; la sed de poder y de dinero no ha tenido límites, como tampoco los han tenido los medios para conseguirlo. No se puede pretender que existan profesiones que por el simple hecho de contar con un código de ética ya estén exentas de hacer parte de esta realidad de ausencia de ética, pues quien las ejerce no es un ser supremo, sino un ser humano rodeado de un ambiente en el que el mundo se convierte en la toalla que seca tristemente muchas de sus más bellas cualidades.

En las organizaciones, la estructura, desde sus diferentes niveles jerárquicos, está amarrada al poder, que, revelado en la historia, pareciera ser una de las causas principales de la existencia de la corrupción. Es como si a mayor poder, mayor tentación y mayor ambición: esta es y ha sido una realidad a la que el contador público no ha sido inmune; es una enfermedad social fácil de contraer, silenciosa, pero cuando se descubre ha contaminado tanto que es difícil de ser curada. 
La contaduría pública, la economía y la administración se han convertido en unas de las profesiones con más egresados desde el año 2001, con un 32\%, según estudio realizado por el periódico El Tiempo en el año $2007^{1}$. No es discutible que la contaduría pública sea una excelente opción al elegir una profesión; lo que valdría la pena evaluar serían las razones por las que se elige, ya que en ocasiones es utilizada para encubrir la consecución de beneficios con actos indebidos, aprovechándose del papel fundamental que tiene en las organizaciones y su función como ojos del Estado en las entidades. ¿Será que la profesión contable necesita anteojos o simplemente se nubla su mirada para no ver lo evidente?

La contaduría pública está envuelta en una profunda oscuridad, y es el contador público el que debe convertirla en la luz que ilumine a las organizaciones, no permitirle que se hunda en esa arena movediza en la que se encuentra y llevarla a tierra firme, donde sea base sólida para la construcción de entidades en las que la bandera de batalla en contra de la corrupción sea la ética; "a pesar que las oportunidades para cometer fraudes existen desde el momento en que se dan una serie de atributos corporativos que permiten la manipulación fraudulenta de los estados financieros (García y Humphrey, 1995: 4).

Sólo cuando se hacen presentes los escándalos en los que los profesionales contables se ven envueltos es cuando se cree que es conveniente limpiar el polvo del baúl de los recuerdos, donde se guarda ese tesoro preciado llamado "ética". Es en dicho momento cuando hay que cuestionarse sobre si para aliviar la carga de la responsabilidad del contador en fraudes efectuados en las organizaciones simplemente basta con orientar la mirada a otra dirección y decir que todo está bien. ¿No es igual de deshonesto este proceder que el hecho de participar directamente en las irregularidades?

Es claro que esta clase de contadores no son la mayoría, son muchos más los que realmente aman la profesión contable; pero la realidad es que por el mal proceder de unos pocos, en este momento existe predisposición sobre lo que realmente significa ser un contador público. Es importante abrir los ojos y ver que la ética debe

1 El Tiempo (2007, 18 de abril). "Carreras con futuro. Nuevos programas conquistan las aulas de las universidades colombianas y otros se reorientan en sintonía con las exigencias del país". Recuperado de http://www.eltiempo.com/archivo/documento/CMS-3518809 
ser el pilar de nuestra profesión, y el dinero debe ser simplemente una añadidura del actuar, mas no la razón de ser. La ética debe constituir nuestro constante punto de referencia, nuestra luz y nuestra fuerza (Zamorano, 2000: 8).

Es triste ver cómo la imagen del contador público se ha ido consumiendo por el mal proceder de algunos; la figura del profesional contable en las organizaciones muchas veces es vista como un mal necesario y no como la solución a múltiples necesidades en la organización. Pero, ¿ cómo juzgar este pensamiento cuando varios contadores lo proclaman y hacen parte de los verdugos de la profesión, dejando sus principios a un lado y, sin ninguna clase de escrúpulos, enlodan no sólo su propia imagen, sino la de todo un gremio?

Es por razones como las expuestas anteriormente por las que se hace evidente la importancia de la ética, constituyéndose ésta en el corazón, el alma y el aire de la profesión contable. La existencia de la fe pública sin ética es simplemente imposible. La realidad colombiana parece indicarnos que no se conoce verdaderamente la esencia de la profesión contable; cada vez es menos frecuente sorprenderse y, por ello, es necesario, igual que un niño, despertar la curiosidad, encontrar en cada escenario una razón para mejorar, en cada universo organizacional buscar un efecto positivo que se expanda a su entorno, dejar a un lado el conformismo, hacer algo extraordinario por rescatar una profesión que es amada por muchos. Actuar con base en los buenos principios brinda algo que el dinero nunca dará: tranquilidad.

El contador público se encuentra en una encrucijada: definirse entre el beneficio de la entidad que lo contrata y la función que debe cumplir al velar por los bienes públicos. Al iniciar la formación contable, los estudiantes se hallan en un universo paralelo en el que asumen que todas las organizaciones cumplen a cabalidad las normas. Pero cuando se transportan a la realidad, despiertan de ese hermoso sueño y tropiezan con situaciones en las que nunca creyeron verse rodeados y para las que en muchas ocasiones no están preparados. Por razones como la mencionada, se resalta la propuesta de Gonzalo y Garvey:

La ética [debe constituirse] como parte integrante de la educación contable. Todas las soluciones contables, y las exigencias de revelación de datos económicos, tienen un trasfondo ético que debe explicitarse, enseñarse y 
discutirse dentro del proceso docente. De esta forma, el futuro comportamiento de los profesionales podrá alinearse con la motivación subyacente (2005, citados en Ariza, 2008: 20).

Son múltiples los problemas que la falta de ética puede traer a la contaduría pública como consecuencia de actos incorrectos, tales como los expuestos en los problemas de comportamiento ético de los profesionales contables. En este orden de ideas, Copeland realiza una “descripción de los problemas (reales o percibidos)", entre los cuales podemos mencionar:

- Colaboración en los fraudes empresariales "amañando los números”.

- Relaciones inapropiadas, consistentes en compartir negocios con los clientes.

- La brecha de expectativas entre la "razonable seguridad" que suministran los auditores y el "aseguramiento" que esperan muchos inversores.

- La falta de coraje profesional, en contables individuales y auditores, para superar las presiones agresivas de los ejecutivos, en su intento de manipular las cifras para conseguir los resultados deseados (citado en Gonzalo y Garvey, 2007: 19).

La profesión contable es una balanza: en un extremo se encuentran los principios y en el otro está el dinero. Es el equilibrio entre estos dos elementos lo que debe buscar el contador público, para de esta manera mantener su independencia y llevar en alto el nombre de su profesión. Pero es preocupante hablar de independencia mental cuando existe una marcada dependencia económica. Dado que el ser contador público no suprime su naturaleza humana ni la existencia de necesidades, entonces cabe cuestionarse: ¿qué tan fácil es dar una opinión, aun sabiendo que asumir una posición ética traerá como consecuencia la pérdida de su sustento económico? ¿Se ha perdido la profundidad en la visión contable o acaso tenemos miopía frente a la ética? 
Es tan importante la ética y la confianza en la profesión contable que es la mejor respuesta a interrogantes como el planteado en 1993 al coronel A.H. Carter, socio principal de Deloitte Haskins \& Sells: "Si los contables auditan a las compañías, ¿quién va a auditar a los contables? La respuesta fue noble y, como se vería, vacía de contenido: nuestra conciencia, contestó el coronel" (Franco, 2002: 22).

\section{Un pasivo que nos está quebrando}

Si hablamos de las organizaciones como un activo, de la corrupción como un pasivo y de la ética como patrimonio, ¿cuál sería el resultado?

Si se observa la realidad económica del país, es evidente cómo la corrupción y los fraudes han crecido significativamente, convirtiéndose en una obligación que tarde o temprano deberá ser cancelada; es en ese momento cuando las consecuencias de los actos de mala fe serán reconocidos, no valdrán lamentaciones y pasará lo inevitable. Esto conlleva a preguntarse: ¿qué sentido tiene vivir un presente con comodidades si al final se terminará en miseria?

Con respecto al activo, puede afirmarse que al inicio se configuran sociedades aparentemente sólidas, con diversas características que las hacen apetecibles, pero al enfrentarse a la realidad de este pasivo tienden a desaparecer, al ser utilizadas para pagar las deudas que generan el fraude, lo que deriva en la pérdida de todo lo que las componen y en ser recordadas posteriormente como empresas que pudieron ser exitosas a través del tiempo, pero eligieron una victoria pasajera con desenlaces trágicos aunque justos.

Entonces, ¿qué pasa con el patrimonio? Se está sacrificando el patrimonio por espejismos, la integridad por algo que realmente no vale la pena. Y esto sucede a pesar de que somos conocedores del riesgo que corremos al invertir lo más preciado: la ética, los principios; todo ello por recibir dividendos enlodados que se desintegran tan rápido como llegan. ¿Será que vale la pena llenarnos de incertidumbre, perder nuestro tesoro y recibir una falsa ilusión? Dice Franco: "La crisis de la confianza genera una real desesperanza en el futuro, deteriora el clima de los negocios, estanca la economía y, aún más, la deprime" (2002: 22). 
Son diversas las situaciones en las que se hubiese podido evitar acontecimientos tan populares, como lo es el caso Parmalat, el que se creía nunca sería descubierto, pero que se convirtió en uno de los grandes escándalos empresariales de la historia. Esta situación generó nefastas consecuencias para los directivos y contadores públicos de la firma Granth Thornton, quienes fueron detenidos y señalados como cómplices, con lo que se deterioró la imagen de un gremio, de una profesión que les entregó todo para alcanzar el éxito, pero que por la falta de principios los llevó al fracaso y a la vergüenza. Es sencillo tomar el camino equivocado, pero, así no parezca, lo es aún más tomar el correcto. "Sólo así, por medio de la transparencia y la rendición de cuentas, se logrará evitar fraudes, como lo fue y lo sigue siendo, pues aún no concluye, el caso de Parmalat" (Gómez y González, 2010: 74).

\section{Encontrando el tesoro perdido: la ética}

La profesión contable está compuesta por diversas áreas: financiera, gestión, auditoría, etc., pero, ¿¿de qué sirve ser expertos en estas áreas si no se posee la piedra más preciada de ese tesoro: la ética?

Durante toda nuestra formación personal y académica se habla sobre la importancia de la ética, de los principios en nuestro proceder, de la integridad, aun cuando vemos cómo nuestro entorno se encuentra invadido por la corrupción, con la que se busca justificar el mal proceder y se muestra una sola cara de la moneda, un supuesto éxito acompañado de una actitud facilista; sin embargo,

hay que poner un gran signo de interrogación sobre el valor de lo fácil; no solamente sobre sus consecuencias, sino sobre la cosa misma, sobre la predilección por todo aquello que no exige de nosotros ninguna superación, ni nos pone en cuestión, ni nos obliga a desplegar nuestras posibilidades (Zuleta, 1980: 6).

La formación académica es clave para que los estudiantes de contaduría sean profesionales íntegros, que no vendan su conciencia por un buen salario u honorarios; pero la ética y la moral no pueden ser sólo una asignatura más: son parte del ser, 
y en nuestra hermosa profesión estos elementos inician desde el momento en que elegimos dedicar nuestra vida a ella. Pero si la intención inicial es simplemente un fin lucrativo,

No es extraño entonces pensar que el papel de las Ciencias Sociales y Humanas en la educación y la formación del Contador Público sea el de formar un espíritu crítico que le permita al estudiante deconstruir (mediante la investigación) y proponer unas nuevas teorías y técnicas para producir información contable, financiera y social capaz de reemplazar las representaciones cosificantes del mundo económico (Rojas, 2007: 17).

La ética no puede ser vista como parte del pasado, debe estar viva y latente en cada uno de nuestros actos, debe brillar como el sol en medio de las tinieblas en la que muchas veces está inmersa nuestra profesión. En ésta hay que combatir actuaciones como aquellas en que las compañías pretenden comprar la conciencia de los profesionales recién egresados por unos cuantos pesos, quienes muchas veces caen en estas trampas simplemente por ingenuidad y desconocimiento de los alcances que tales situaciones implican y las consecuencias que trae consigo una mala decisión. ¿Cómo reducir el riesgo de ser víctimas de nuestra ingenuidad e inexperiencia? Parte de la respuesta puede ser el trabajo en equipo entre estudiantes y docentes, en el cual "la comprensión del alumno por parte del maestro modela en buena parte la comprensión recíproca y la autocomprensión de uno y otro" (Federici et ál. 1984: 12).

“PPudo la ética haber prevenido la crisis económica actual y puede evitar que aparezcan nuevas crisis en el futuro? Sí, pero no la ética en abstracto, sino ética incorporada en los objetivos, estructuras y culturas de las organizaciones" (Argandoña, 2010: 9). Los estudiantes de contaduría pública son el futuro de la profesión, quienes se enfrentarán a nuevas circunstancias en las que se pondrán a prueba sus principios, lo que hace evidente la necesidad de llevar a las aulas de clase un conocimiento integral en el que la ética se convierta en una prioridad.

La ética no sólo es una asignatura, es la que le da sentido a la existencia misma de la contaduría pública y, aun así, es notorio cómo no se le da el valor suficiente, no se ve como lo que es: un tesoro invaluable. Tener la conciencia tranquila y mantener 
nuestros principios, por difícil que parezca, basando la formación y práctica de la profesión en la ética personal y profesional, es lo que mantendrá viva la contaduría pública."Incorporar la dimensión ética en la formación del contador implica recuperar para ella una visión más integrada de la persona” (Aquel, 2010: 10).

\section{Epílogo: una invitación a la pasión por lo contable}

En árido desierto, bajo el sol inclemente, aparecen ante nuestros ojos, de la nada, espejismos que buscan desviarnos del camino que nos lleva al oasis que tanto anhelamos. La contaduría brinda múltiples caminos, pero la corrupción también brinda los suyos; nosotros decidimos.

La contaduría pública es un planeta lleno de pureza, protegido con una capa ética, pero deteriorado por la contaminación llamada corrupción, que busca convertir el paraíso en seco desierto, en el que la sed incontrolable del dinero y del poder es el inicio de la autodestrucción.

Contabilidad y ética deben ser joyas brillantes, llenas de excepcionales principios, no baratijas de mísero valor, despreciadas sin razón.

La ética no es una máscara ni un disfraz para aparentar; la ética debe ser la bandera que a la batalla voy a llevar.

La contaduría pública no es cuadro con lineamientos inamovibles, es un algo único, flexible y rígido a la vez, que brinda infinidad de oportunidades de alcanzar lo sueños sin perder el ser. 
Al culminar el reflejo de una sola realidad, vista desde diferentes escenarios nos encontramos con una misma conclusión: la corrupción opaca todo ser, le hemos permitido ser tan fuerte que ha ganado batallas contra la integridad de la sociedad. Pero la guerra no ha terminado, aún podemos salir victoriosos, con la frente en alto; lo único que tenemos que hacer es despertar y darnos cuenta que el poder y el dinero son importantes, pero no son el todo que nos satisface.

Si el poder y el dinero brindaran felicidad y llenaran nuestros vacíos, ¿ por qué cada vez queremos más? La realidad es que dejamos de tener una existencia tranquila por una satisfacción pasajera que al final nos dejará igual o más vacíos. No se está llamando al conformismo o a criticar las comodidades y beneficios que brindan los bienes materiales, sino que observemos en lo que nos estamos convirtiendo: una sociedad fría y sin escrúpulos.

La ética no es un chip que nos implantan en el cuerpo, ni una programación que nos imponen al nacer. La ética es parte de la formación constante, y el conservarla debe ser tan importante como el respirar. Entonces, ¿ por qué morir en vida al vender nuestra conciencia? La ética es el corazón de la profesión contable, y depende de todos los apasionados por ésta que no pare de latir.

A veces parece difícil sobrevivir en esta selva, donde triunfa el más "fuerte" y muchas veces hacer lo correcto nos hace débiles y el pasar por encima de los demás nos fortalece. ¿Qué de humano tiene ese pensamiento? Sin embargo, "la teoría del apoyo mutuo genera relaciones sinérgicas a partir de alianzas que promueven el trabajo en equipo legitimado a partir del diálogo" (León, 2010: 12).

Se habla del contador público como un profesional "cuadriculado", pero, ¿acaso no se han presentado avances en la contabilidad de gestión respecto al impacto en la dirección estratégica? El punto es por qué no usar esa creatividad para la innovación contable y no para el deterioro de su imagen.

El contador público debe ser consciente de que la profesión contable es teóricopráctica, y "la práctica es la transformación intencional del mundo a partir de un modelo de compresión del mismo" (Gómez, 2006: 6), es decir, el contador cuenta con todo lo necesario para hacer cambios extraordinarios, sólo debe decidirse. 
¿Por qué no enamorarse de la profesión a la que le entregamos nuestra vida? ¿Por qué traicionar nuestra profesión si ella nos entrega todo de sí? El futuro está en nuestras manos.

\section{Referencias}

Ariza, E.D. (2008). Transformaciones contextuales, disciplinares y de pénsum de Contaduría Pública: un análisis relacional. Bogotá: Universidad Militar Nueva Granada.

Aquel, S. (2010). La ética como eje transversal en la formación del contador público. Actualidad Contable Faces, 13(21), 5-16. Mérida: Universidad de los Andes. Recuperado de http://redalyc.uaemex.mx/redalyc/pdf/257/25718409002.pdf

Argandoña, A. (2010). La dimensión ética de la crisis financiera. Bussines School. Universidad de Navarra. Recuperado el 20 de enero de 2011 desde http://www. iese.edu/research/pdfs/DI-0872.pdf

Cruz Kronfly, F. (2005). Las palabras y los gestos en el tejido organizacional. Recuperado de http://www.infoweb2.unp.edu.ar/posgrado/Documentos/ materias/Management\%20Estrategico/Williams\%20Rojas\%20Rojas/ Sesi\%C3\%B3n\%205/Las\%20palabras\%20y\%20los\%20gestos\%20en\%20el\%20 tejido\%20organizacional.\%20Fernando\%20Cruz\%20Kronfly.pdf

Federici, Mockus, Charum, et.ál. (1984). Límites del cientificismo en educación. Recuperado de http://www.pedagogica.edu.co/storage/rce/articulos/14_08pole. pdf

Franco Ruiz, R. (2002). Réquiem por la Confianza, escándalos empresariales, negocios y contaduría. Pereira: Investigar Editores.

García, M. y Humphrey, C. (1995). La auditoría y el fraude: algunas consideraciones internacionales. Revista Española de Financiación y Contabilidad, XXIV (84), 697-726. Recuperado de http://www.aeca.es/pub/refc/articulosi. php?id=0378 
Gómez Álvarez, D. y González, V. (2010). La leche es blanca pero no transparente. Parmalat, breve recuento de un gran fraude. México: Instituto de Investigaciones Jurídicas. Recuperado de http://www.bibliojuridica.org/libros/5/2456/5.pdf

Gómez Villegas, M. (2006). Comentarios sobre el aprendizaje-construcción de la teoría contable. Recuperado de http://administracion.univalle.edu.co/ Comunidad/Memorias/evento1/archivos/Comentarios\%20sobre\%20el\%20 aprendizaje\%20construccion\%20de\%20la\%20teoria\%20contable.pdf

Gonzalo, J.A. y Garvey, A.M. (2007). Ética y enseñanza de la contabilidad (una propuesta de discusión). Contaduría-Universidad de Antioquia, 50, 11-42. Recuperado de http://contaduria.udea.edu.co/proyecto/archivos/rec/doc/ Etica\%20y\%20ensenanza\%20-\%20Gonzalo\%20y\%20Garvey.pdf

León,J.C.(2010). Responsabilidad social empresarial y cadena de valor. Reconstrucción de conceptos para una aproximación a una gestión más humana. Memorias XLV de la Asamblea CLADEA 2010. Recuperado de http://www. cladea2010.org/memorias_cladea2010/index.html

Ospina,W.(1997).¿Dónde está la franja amarilla? Bogotá: Grupo Editorial Norma. Recuperado de http://books.google.com.co/books?hl=es\&lr=\&id=NPoXhTm 2jaUC\&oi=fnd\&pg=PA5\&dq=donde+est $\% \mathrm{C} 3 \% \mathrm{~A} 0+\mathrm{la}+$ franja + amarilla\&ots =t0vik6-lW8\&sig=I-xexJ_7fHo7k8cQr0dyore32QQ\# $\mathrm{v}=$ onepage \&q\&f=false

Rojas, W. (2007).Contribución de las ciencias sociales y humanas a la formación del Contador Público. Recuperado de http://administracion.univalle.edu. co/Comunidad/Memorias/evento1/archivos/Contribucion\%20de\%20las\%20 ciencias\%20sociales\%20y\%20humanas\%20a\%20la\%20formacion $\% 20 \mathrm{del} \% 20$ contador\%20publico.pdf

Ruiz, G.J. (2008). Las normas internacionales de contabilidad y la contabilidad creativa. Cuadernos de Contabilidad, 9(24), 251-301. Pontificia Universidad Javeriana. Recuperado de http://www.javeriana.edu.co/fcea/cuadernos_contab/ vol9_n_24/vol9_24_9.pdf 
Sánchez, R. (2009). Circunstancias relevantes que podrían estar asociados al fraude contable en la interacción de los auditores y las empresas. Arequipa. Recuperado de http://www.ucsp.edu.pe/images/investigacion/circunstanciasrelevantes.pdf

Zamorano, E. (2000). Transparencia y corrupción. Banco Interamericano de Desarrollo, Conferencia sobre Transparencia y Desarrollo en América Latina y el Caribe. Recuperado de http://199.79.166.188/leg/Seminar/Documents/ Transparencia\%20Zamorano\%20Spa.pdf

Zuleta, E. (1980). Elogio de la dificultad. Recuperado de http://colectivocores. entodaspartes.net/files/2009/05/elogio-de-la-dificultad.pdf 